\title{
THE EFFECT OF VENTRICULIN ON THE BLOOD SUGAR LEVEL IN PATIENTS WITH PERNICIOUS ANEMIA
}

\author{
By S. MILTON GOLDHAMER
}

(From the Thomas Henry Simpson Memorial Institute for Medical Research, University of Michigan, Ann Arbor)

(Received for publication February 17, 1932)

A reduction of the blood sugar content, analogous to that produced by insulin, was noted by Blotner and Murphy (1) after administration of whole liver and certain of the liver fractions ineffective in the treatment of pernicious anemia. Fractions G, an effective liver extract prepared by Cohn and his collaborators (2), appeared to contain little if any blood sugar reducing substances. An observation repeated by Riddle (3) substantiated the evidence that this liver extract contained no specific blood sugar reducing properties. After the introduction by Sturgis and Isaacs of ventriculin as a specific treatment in pernicious anemia (4), it was decided to determine whether or not this preparation possessed blood sugar reducing properties similar to those of whole liver.

The blood sugar level was determined on eleven patients with pernicious anemia at frequent intervals during treatment with ventriculin, liver extract, and on one patient in spontaneous remission. The samples of blood were obtained under fasting conditions at $8 \mathrm{~A} . \mathrm{M}$., and the blood sugar values were estimated according to the micro method of Folin and $\mathrm{Wu}$ (5). Each patient was given 40 grams of ventriculin daily, and observations were made during the interim of the rise of the reticulated red blood cell count, at intervals of one to two days. Data on the red blood cell counts, hemoglobin and reticulocyte percentage were also recorded.

The fasting blood sugar values obtained during the treatment with ventriculin are listed in Table I. The results for each patient are recorded separately, showing daily variations as well as the general trend. With two exceptions, the initial values were within the range of 84-135 mgm. of sugar per $100 \mathrm{cc}$. of blood-the majority of the results bordering on the upper limits of normal. Six to ten days after the onset of treatment, the blood sugar values in each case reached their lowest levels, the decrease being gradual. These minimal readings were within the range of $61-97 \mathrm{mgm}$. The average decline of the blood sugar level was about $45 \mathrm{mgm}$. per cent, the upper and lower extremes being 30 and 60 mgm. In the series of cases which were studied during the entire period of the rise and fall of the reticulated cell count, the blood sugar levels 
TABLE I

Milligrams sugar per 100 cc. of blood

\begin{tabular}{|c|c|c|c|c|c|c|c|c|c|c|c|c|}
\hline \multirow{3}{*}{$\begin{array}{c}\text { Days of } \\
\text { treatment }\end{array}$} & \multicolumn{11}{|c|}{ Ventriculin treated patients } & \multirow{3}{*}{$\begin{array}{c}\text { Spontaneous } \\
\text { remission }\end{array}$} \\
\hline & \multicolumn{11}{|c|}{ Patient number } & \\
\hline & 1 & 2 & 3 & 4 & 5 & 6 & 7 & 8 & 9 & 10 & 11 & \\
\hline $\begin{array}{r}-2 \\
-1 \\
0 \\
1 \\
2 \\
3 \\
4 \\
5 \\
6 \\
7 \\
8 \\
9 \\
10 \\
11 \\
12 \\
13 \\
14 \\
15\end{array}$ & $\begin{array}{c}m g m \\
\\
131 \\
110 \\
137 \\
110 \\
\\
111 \\
103 \\
95 \\
100 \\
104 \\
143 \\
108 \\
97.5 \\
\\
121 \\
\\
121\end{array}$ & \begin{tabular}{|r}
$m g m$ \\
\\
107 \\
102 \\
107 \\
\\
98 \\
95 \\
104 \\
83 \\
80 \\
78 \\
75 \\
84 \\
111 \\
109 \\
148 \\
118
\end{tabular} & \begin{tabular}{|c|} 
mgm. \\
92 \\
99 \\
85 \\
85 \\
\\
75 \\
68 \\
75 \\
70 \\
61
\end{tabular} & \begin{tabular}{|r}
$m g m$. \\
\\
135 \\
130 \\
120 \\
143 \\
125 \\
\\
106 \\
105 \\
107 \\
93 \\
86 \\
102 \\
\\
114 \\
\\
108
\end{tabular} & \begin{tabular}{|r} 
mgm. \\
138 \\
\\
135 \\
120 \\
138 \\
151 \\
135 \\
106 \\
95 \\
94 \\
105 \\
94 \\
100 \\
117 \\
\\
109 \\
115
\end{tabular} & \begin{tabular}{|r}
$m g m$. \\
109 \\
115 \\
137 \\
\\
105 \\
102 \\
97 \\
100 \\
111 \\
83 \\
72 \\
95 \\
102 \\
\\
105 \\
\\
125
\end{tabular} & \begin{tabular}{|c} 
mgm. \\
\\
118 \\
120 \\
117 \\
117 \\
103 \\
101 \\
105 \\
93
\end{tabular} & \begin{tabular}{|c}
$m g m$. \\
124 \\
115 \\
109 \\
138 \\
121 \\
\\
131 \\
125 \\
121 \\
97
\end{tabular} & \begin{tabular}{|c} 
mgm. \\
84 \\
\\
90 \\
78 \\
85 \\
87 \\
81 \\
75 \\
80
\end{tabular} & \begin{tabular}{|c}
$m g m$. \\
94 \\
96 \\
95 \\
94 \\
94 \\
89 \\
93 \\
85 \\
95 \\
89 \\
95
\end{tabular} & $\begin{array}{c}m g m . \\
\\
114 \\
108 \\
\\
117 \\
\\
100 \\
95 \\
105\end{array}$ & $\begin{array}{r}133 \\
91 \\
91 \\
101 \\
103\end{array}$ \\
\hline
\end{tabular}

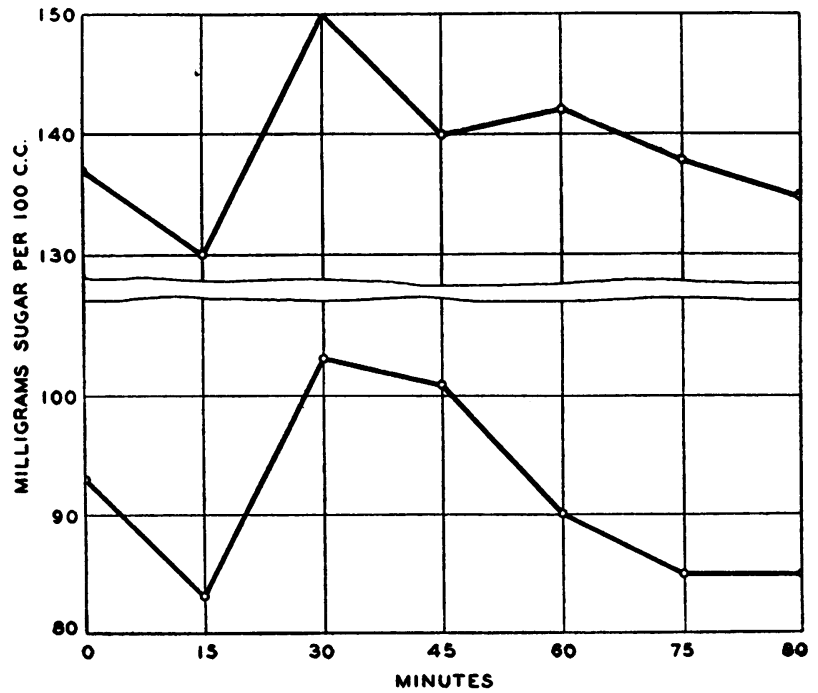

Fig. 1. Effect of Ingestion of 40 Grams of Ventriculin on Blood Sugar Level of Two Patients with Pernicious Anemia 
reached their lowest values at the time of the peak of the reticulated red blood cell percentage rise, subsequently undergoing a gradual upward swing but not quite attaining their initial values in the majority of cases.

In two cases an attempt was made to determine any immediate effect of the ingestion of ventriculin on the blood sugar level. Blood samples were taken before and at intervals of 15 minutes for one and a half hours after the administration of 40 grams of ventriculin. These results are shown in Figure 1. The first specimens showed a slight decrease of 7-10 mgm., followed by an increase which attained its maximum in the onehalf hour specimens. The values declined to approximately their original levels within one hour. The immediate effect of the administration of 40 grams of ventriculin was a slight increase in the blood sugar level, similar to that occurring after the ingestion of any other similar food substance.

Following treatment with ventriculin, as with liver extract, a marked increase of appetite was noted in each of the cases. For 2-4 days after the onset of treatment with ventriculin, no change in the appetite was observed; however, with the beginning of the reticulocyte response, a noticeable increase was evident. The usual diet which was more than sufficient during the first few days was supplemented with extra nourishment. Often the patients were given high caloric diets to appease their hunger. Inasmuch as the majority of the patients often lose weight in early remission, due probably to water loss (6), the weight factor could not be used in correlation with the hunger symptoms.

As the symptoms of hunger seem to be associated with both the increase of reticulated red blood cells and the amount of sugar present in the blood, the correlation of these two values is of interest. Determinations of the reticulocyte percentage and blood sugar values of three cases are recorded in Table II. Case 1 was treated with ventriculin, Case 2 with liver extract. Each was selected as representative of a series of ten cases similarly treated. Case 3 is one of pernicious anemia in spontaneous remission. If the blood sugar values are plotted together with the reticulated red blood cell percentage of the same day (Figures 2 and 3), it is noted that the lowest blood sugar level occurs simultaneously with the peak of the reticulocyte percentage rise. Apparently this behavior is physiologic, as it is always present regardless of the type of treatment, or if the remission is spontaneous. It is fair to conclude from this that the reduced sugar level is the result of increased metabolic activity of the bone marrow, as manifested by the increase of young red blood cells in the stream; or, that the reduced sugar values are the result of the increased metabolic activity of the young red cells themselves; or both. Riddle (3) stated that the cause for the lowered fasting blood sugar values during early remission was speculative, and that the evidence pointed to some unknown metabolic process. This process is now thought to be 


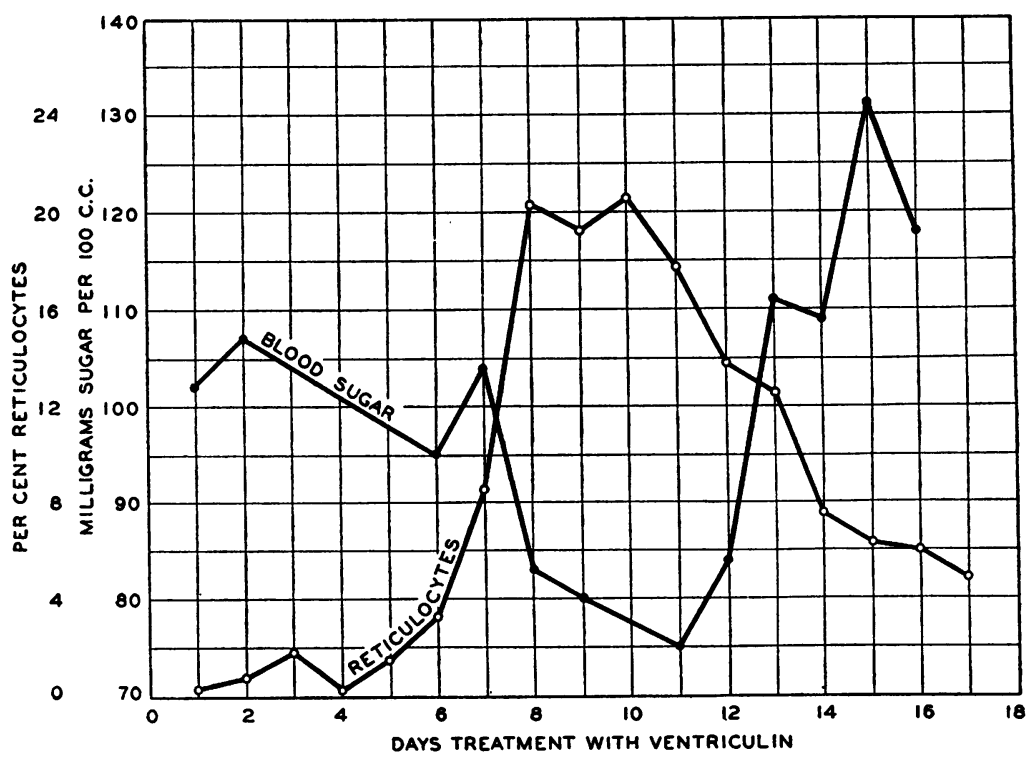

Fig. 2. Relationship of Blood Sugar and Reticulocytes following VENTRICULIN THERAPY

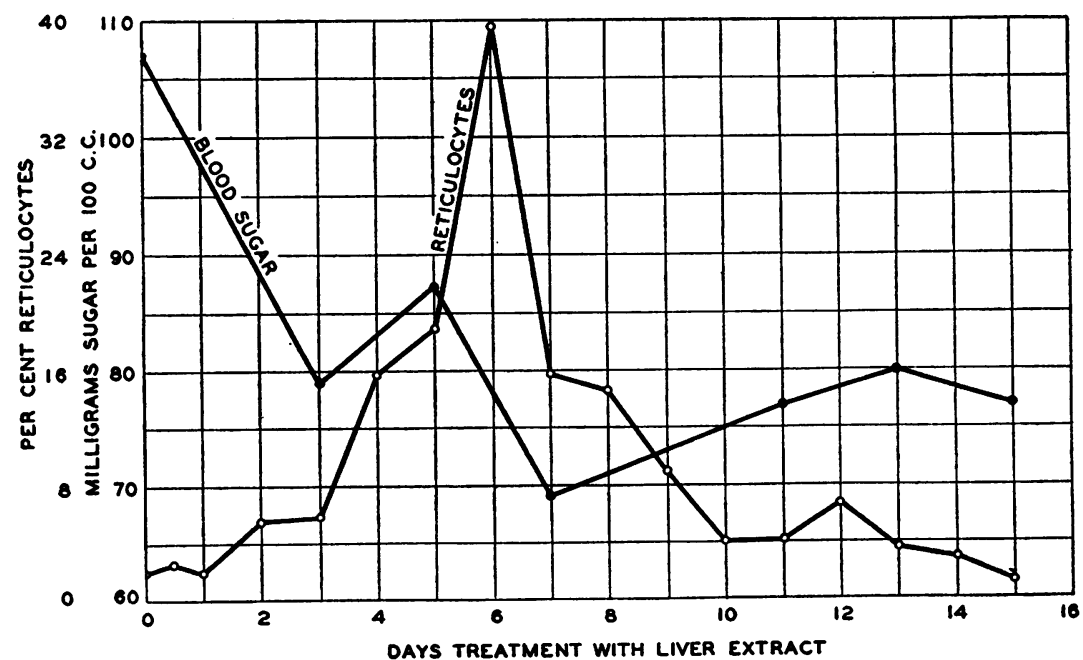

Fig. 3. Relationship of Blood Sugar and Reticulocytes Following Liver EXTract Therapy 
TABLE II

Fasting blood sugar values during treatment with ventriculin, liver extract and spontaneous remission

\begin{tabular}{|c|c|c|c|c|c|c|}
\hline \multirow{2}{*}{$\begin{array}{l}\text { Days } \\
\text { of } \\
\text { obser- } \\
\text { vation }\end{array}$} & \multicolumn{2}{|c|}{ Case $1 *$} & \multicolumn{2}{|c|}{ Case 2 * } & \multicolumn{2}{|c|}{ Case 3 * } \\
\hline & Blood sugar & Reticulocytes & Blood sugar & Reticulocytes & Blood sugar & Reticulocytes \\
\hline $\begin{array}{r}-4 \\
-3 \\
-2 \\
-1 \\
0 \\
1 \\
2 \\
3 \\
4 \\
5 \\
6 \\
7 \\
8 \\
9 \\
10 \\
11 \\
12 \\
13 \\
14 \\
15\end{array}$ & $\begin{array}{r}107 \\
102 \\
107 \\
\\
98 \\
95 \\
104 \\
83 \\
80 \\
78 \\
75 \\
84 \\
111 \\
109 \\
148 \\
118\end{array}$ & $\begin{array}{r}\text { per cent } \\
\\
\\
.8 \\
.2 \\
.8 \\
1.9 \\
.3 \\
1.5 \\
3.2 \\
8.5 \\
20.1 \\
19.2 \\
20.3 \\
17.6 \\
13.8 \\
12.1 \\
7.5 \\
6.4 \\
6.0\end{array}$ & $\begin{array}{c}\text { mgm. per } \\
100 \text { cc. } \\
93 \\
88 \\
\\
107 \\
\\
\\
79 \\
87 \\
\\
69 \\
\\
\\
77 \\
80 \\
80 \\
77\end{array}$ & $\begin{array}{c}\text { per cent } \\
2.3 \\
1.4 \\
2.0 \\
2.1 \\
2.5 \\
2.0 \\
5.2 \\
5.7 \\
15.9 \\
18.0 \\
39.5 \\
15.1 \\
14.6 \\
9.0 \\
4.3 \\
4.3 \\
5.8 \\
3.8 \\
3.1 \\
2.2\end{array}$ & $\begin{array}{r}133 \\
91 \\
91 \\
101 \\
103\end{array}$ & $\begin{array}{r}7.5 \\
10.2 \\
17.9 \\
18.4 \\
11.9 \\
9.6 \\
9.6 \\
7.3 \\
8.0 \\
6.8 \\
5.5 \\
2.2\end{array}$ \\
\hline
\end{tabular}

* Case 1-40 grams ventriculin daily.

Case 2-6 vials Lilly's liver extract daily.

Case 3-Spontaneous remission.

the increased activity of immature red blood cells, of the bone marrow, or a combination of the two.

The results obtained have been made from observations, which disregard the blood volume factor. The influence of the blood volume on the concentration of the blood sugar levels is not known at this time. However, its importance and significance are being studied.

\section{SUMMARY AND CONCLUSIONS}

1. In pernicious anemia in relapse, the blood sugar values are usually within the upper limits of normal.

2. The decreased blood sugar values in the beginning of a remission occur at the time of the increase in the percentage of immature red blood cells present in the peripheral circulation.

3. The blood sugar level reaches its lowest value at a time corresponding with the peak of the reticulated red blood cell percentage rise.

4. In early remission the blood sugar level may fall as low as $61 \mathrm{mgm}$. 
per $100 \mathrm{cc}$ - - practically all the values were within the lower limits of normal.

5. The onset of hunger symptoms in early remission may be directly associated with the decrease in the blood sugar level-the result of increased metabolic activity of either the marrow, the immature red blood cells, or both.

6. With general improvement, the blood sugar values increase and maintain themselves at a level not quite as high as their original one.

7. Ventriculin has no specific insulin-like properties when taken by mouth - the immediate effect following ingestion of $\mathbf{4 0}$ grams is a slight increase in the blood sugar value for about one-half hour, with a gradual return to its original level.

\section{BIBLIOGRAPHY}

1. Blotner, Harry, and Murphy, William P., J. Am. Med. Assoc., 1930, xciv, 1811-16. Effect of Certain Liver Extracts on the Blood Sugar of Diabetic Patients.

Blotner, Harry, and Murphy, William P., J. Am. Med. Assoc., 1929, xcii, 1332-36. The Effect of Liver on the Blood Sugar Level.

2. Cohn, E. J., Minot, G. R., Alles, G. A., and Salter, W. T., J. Biol. Chem., 1928, lxxvii, 325. The Nature of the Material in Liver Effective in Pernicious Anemia.

3. Riddle, Matthew C., Ann. Int. Med., 1930, iii, 1097. The Blood Sugar during Remission in Pernicious Anemia.

4. Sturgis, Cyrus C., and Isaacs, Raphael, J. Am. Med. Assoc., 1929, xciii, 747-9. Desiccated Stomach in the Treatment of Pernicious Anemia.

5. Folin, O., and Wu, H., J. Biol. Chem., 1920, xli, 367. A System of Blood Analysis: Supplement 1. A Simplified and Improved Method for Determination of Sugar.

6. Vaughan, Janet M., Arch. Int. Med., 1931, xlvii, 688. The Gain in Body Weight Associated with Remissions in Pernicious Anemia. 